\title{
THE MICROBIAL FLORA OF THE DIFFERENT GUT REGIONS OF THE VARIEGATED GRASSHOPPER ZONOCERUS VARIEGATUS (L) (ORTHOPTERA: PYRGOMORPMIDAE
}

IDOWU A. BABATUNDE and EDEMA M. OLAYINKA

(Received 9 March 2001; Revision accepted 18 October 2001)

\begin{abstract}
The microbial flora of the gut regions and gut contents of the variegated grasshopper Zonocerus variegatus instars was studied using the pour plate technique. The gut sections (Fore-, mid-, and hindgut) harboured a variety organisms mainly bacteria, fungi and mould. Yeasts species isolated were Candida, Saccharomyces and Pichia spp. Aspergilus, Penicillium, Fusarium and Rhizopus spp. Both gram positive and gram negative bacteria were isolated. The gram negative bacteria isolated were mainly rods and members of the family Enterobacteriaceae including Proteus, Alcaligenes, Escherichia and Serratia. These species were more widely distributed in and more frequently isolated from the gut regions and their contents than the gram positive bacteria which were represented by Sreptocoscus, Lactobacillus and Staphylococcus species. Gram positive bacteria were isolated from the gut extracts of the $3^{\text {rd }}$ and $4^{\text {th }}$ instars but were found in some of the gut regions of the $6^{\text {th }}$ and adult instars. Mould population decreased gradually as the grasshopper was moulting from the $3^{\text {rd }}$ to adult instars. Ranking according to microbial load was adult $>6^{\text {th }}>4^{\text {th }}>3^{\text {ri }}$, a reflection of their gut capacity since the microbes were part of the diet. The number and types of microbes in the gut regions of these instars are similar but significantly different in terms of total microbial load $(P \geq 0.05)$. The results of this study could provide a lead into the proper understanding of the physiological processes involved in the digestion of plant materials by the insect.
\end{abstract}

Keywords: Z.variegatus, microbial, bacteria, mould, yeast, gut

\section{INTRODUCTION}

\section{Zonocerus variegatus (Orthoptera:} Pyrgomorhidae), the variegated grasshopper is an insect that is aposematically coloured, sequesters toxic chemicals from plants (Chapman et a., 1986). The insect commonly lives in dense groups and has a repellent gland, which is situated in the $1^{\text {st }}$ and $2^{\text {nd }}$ abdominal segments (Idowu, 1995). The grasshopper is a polyphagous with the early instars feeding on Chromolaena odorata (Siam weed) while the later instars prefer Manihot esculenta (Cassava) (Chapman et al., 1986).

Literature review has shown that relatively few studies on the physiology of $Z$.variegatus has been carried out, indicating, that very little is known on the physiology of its digestive process (Idowu, 1994). Although, Balogun (1972) and Modder (1977) reported the presence of glycosidase enzymes in the gut homogenate of Z.variegatus, the functions of these enzymes and the mechanisms of digestion of the food eaten by the grasshspper are yet to be studied. In addition to their abili, to secrete enzymes for the digestion of their food, some insects are known to harbour microorganisms in their digestive tract that assist in the digestion of components of the insect's food (Mead et al 1988). For example, the gut of the adult locusta Schistocerca gregaria has a wide range of bacterial types with the predominant flora in the midgut and hindgut regions being members of the family Enterobacteriaceae and motile Streptococci (Hunt and Charnley 1981). There is however no information in the microbial flora of the gut of Zonocerus variegatus. This study is therefore aimed at studying the ecology of the microbial flora of the gut region of some instars of $Z$.variegatus, as well as the microbial of their gut content.

Materials and Methods

Collection and Preparation of Specimen: Twenty 
.0) grasshoppers were used in this study 15 for each instar). The freshly collected grasshoppers from the field were kept in aerated containers at refrigerated temperature until dissection to prevent regurgitation of gut contents. They were kilied by breaking the cervical membrane and thus severing the ventral nerve cord. Each grasshopper was surface sterilized by swabbing with a tincture of iodine followed by $70 \%$ ethanol. The body cavity was opened by a ventral longitudinal incision. The gut was partitioned in situ into 4 sections by means of double ligatures placed between the foregut and midgut, midgut and hindgut, midgut and gastric caeca, using a flamed forcep. The different regions were separated by cutting between the ligatures. The hindgut was freed of malpighian tubules so as to exclude microogrnism inhabiting the tubule which are not necessarily concerned with digestion of food materials. The gut contents of the various parts were emptied into labelled petri dishes while the walls were washed thoroughly with distilled water to free it from any adhering material. The gut contents were then added to the distilled water used for washing the gut walls. Using a glass homogeniser with a Tefion pestle, each gut section was then highly homogenized in $1 \mathrm{ml}$ of sterile distilled water. They were decanted into labelled screw-capped bottles containing $4 \mathrm{ml}$ sterilized water.

Microbiological analyses: From all samples, $1 \mathrm{ml}$ sub-sample was homogenized in $9 \mathrm{ml}$ sterile water and ten fold serial dilutions wert made. $0.1 \mathrm{ml}$ aliquot of each sample was inoculated by the pour plate technique using the following: Potato Dextrose Agar (PDA, Difco, USA) to which $0.01 \%(\mathrm{w} / \mathrm{v})$ sterile oxytetracycline was added after autoclaving. This was used for enumeration of fungi. Nutrient agar (NA) and deMann Rogosa Sharpe medium (MRS) (Oxford, England) were used for enumeration of bacteria. PDA plates were incubated at $30^{\circ} \mathrm{C}$, 5days while NA and MRS plates were incubated at $37^{\circ 0}$ for 5 days.

Viable Counts:At intervals depending on the medium, the colony forming units (cfu) were determined using the pour plate method. Bacterial counts were made on plate count agar while fungal counts were made on PDA medium (adjusted to $\mathrm{pH}^{3.5}$ with lactic acid).

Characterization of the Microflora: Purified colonies were grouped according to their colony morphology and cell characteristics. Yeasts and moulds were identified from their micromorphology after staining with cotton blue lactophenol. Yeasts isolates further identified according to Kreger-Van rij (1984) by pseudomycelium formation and pattern of sugar fermentation (glucose, galactose, maltose, lactose and raffinose) as well as growth at $37^{\circ} \mathrm{C}$. The bacterial isolates were identified using Bergey's manual of Systematic bacteriology (Sneath et al, 1986) and the methods of Hugh and Leifson (1953) and Harrigan and MacCance (1976).

Statistical Analysis: A comparism of mean microbial population obtained from the different instars was carried out by means of ANOVA and $t$-test $(P \geq 0.05)$

\section{RESULTS}

Microbial Counts: The highest number of colony forming units were found in the adult instar, for all groups of organisms. Counts of yeasts ranged from $1.4 \times 10^{4}$ to $4.3 \times 10^{4}$; bacterial from $2.3 \times 10^{4}$ to $8.3 \times 10^{4}$ and mould counts from $0.3 \times 10^{4}$ to $1.6 \times 10^{4}$ (Table 1 ).

The $6^{\text {th }}$ instar had the next highest numbers of microorganisms with yeasts counts ranging from $1.7 \times 10^{4}$ to $2.8 \times 10^{4}$ in both the foregut and gastric caeca; mould counts ranged from $0.2 \times 10^{4}$ to $1.2 \times 10^{4}$ and bacterial counts ranged from $0.7 \times 10^{4}$ to $4.7 \times 10^{4}$. However moulds were not detected in the fore and mid gut as well as the gastric caeca of the $6^{\text {th }}$ instars. Yeasts count in the $4^{\text {th }}$ instar ranged from $0.4 \times 10^{4}$ to $2.0 \times 10^{4}$; bacterial from $0.3 \times 10^{4}$ in the midgut and hindgut to $2.6 \times 10^{4}$ in the gastric caeca and mould from $0.1 \times 10^{4}$ in the mid-and hind-gut contents to $0.4 \times 10^{4}$ in the gastric caeca. Moulds were not detected in the foreand hindguts of the $4^{\text {th }}$ instar. The $3^{\text {rd }}$ instar generally had the lowest number of microorganisms. Yeast counts ranged from $0.2 \times 10^{4}$ to $0.8 \times 10^{4}$; bacterial from $0.3 \times 10^{4}$ to $2.1 \times 10^{4}$ and mould from $0.4 \times 10^{4}$ in the foregut and gastric caeca to $1.3 \times 10^{4}$ in the contents of the hindgut. There was no significant difference between the total microbial counts of the adult and $6^{\text {th }}$ instars in all the different gut regions $(P \geq 0.05)$. Also, no significant difference was recordad for the total population of microbes obtained in the gut of the $3^{\text {rd }}$ and $4^{\text {th }}$ instars $(P \geq 0.05)$. 


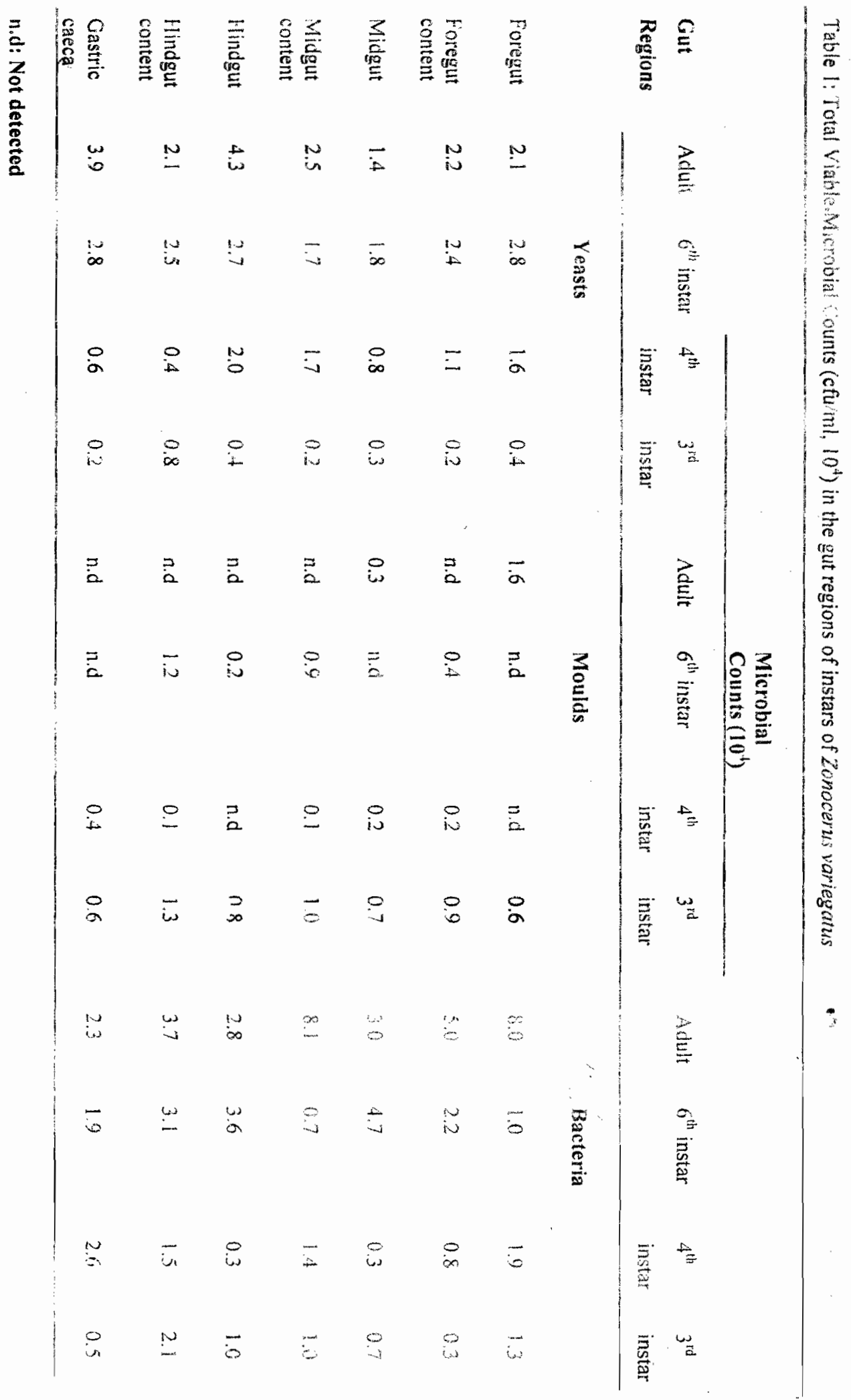


Characterization of Micro flora: Yeast isolates were identified as Candida, Saccharomyces and Pichia. One of the Saccharomyces sp. Was identified as S.cerevisae. Four genera of moulds were isolated: Aspergilus, Pencicillum, Fusarium and Rhizopus sp. The gram-positive non-motile rods and cocci were identified as Staphylococcus (catalase + ve cocci producing acid from glucose but not from lactosel. Streptococcus (catalase -ve cocci producing acid from both glucose and lactose) and Lactobacillus (catalase - ve rods producing acid from both glucose and lactose). Gram-negative motile and non-motile rods were members of the family Enterobacteriaceace and identified as Proteus, Alcaligenes, Escherichia, Enterobacter, Pseudomonas and Serratia sp. The list of isolated micro flora in the different instars is shown on Table 2.

Distribution of micro flora: Table 3 shows the distribution of the various yeasts, mould and bacterial isolates in the various gut regions of the four instars examined. Among the yeasts isolates Candida $s p$ was the most widely distributed organism in all the gut regions of the different stages of the insect examined and most frequently isolated. This was followed by S.cerevisiae, Pichia sp being the least commonly isolated. There was no particular trend in the distribution of the mould flora. Gram-positive bacteria were not isolated from the $3^{\text {rd }}$ and $4^{\text {th }}$ instars while they were isolated in some regions in both the adult and the $6^{\text {th }}$ instar, occurring more in the adult than in the $6^{\text {th }}$ instar. Gram-negative bacteria were more frequently isolated than the gram positive bacteria. Of the Enterobacteria, E.coli was most commonly distributed in all the regions of the $3^{\text {rd }}$ and $4^{\text {th }}$ instar while Alcaligenes was widely distributed in the gut regions of the $6^{\text {th }}$ instar.

\section{DISCUSSION}

A variety of microorganisms were isolated from the gut regions of the four developmental stages of Z.variegatus examined in the present study (Tables $2 \& 3$ ). These results show that the gut of the grasshopper is rich with a variety of microoganisms. Comparable results were obtained by Hunt and Charnley (1981) and

Table 2: List of isolated microflora (bacterial and fungi) from Zvariegatus

\begin{tabular}{|c|c|c|c|c|c|}
\hline & Bactiria & & Yeasts & & Moulds \\
\hline Isolates code & ldtentity & Isolates code & Identity & Isolates code & Identity \\
\hline 3 & Prolcus sp & $Y^{i}$ & Candida sp & $\mathrm{MI}$ & Aspergillus \\
\hline BII & Alcaligens sp & YII & $\begin{array}{l}\text { Saccharomyces } \\
\text { cerevisae }\end{array}$ & MII & Penicillum sp \\
\hline BIII & Streptococcus sp & Yll & Saccharomyces sp & Mill & Fusarium sp \\
\hline BIV & Esherichia coli & YIV & Pichia sp & MIV & Rhizopus \\
\hline$B V$ & L.aciobacillus sp & & & & \\
\hline BVI & Enterobacter sp & & & & \\
\hline BVII & Pseudomonas & & & & \\
\hline BVIII & Staphylococcus sp & & & & \\
\hline
\end{tabular}




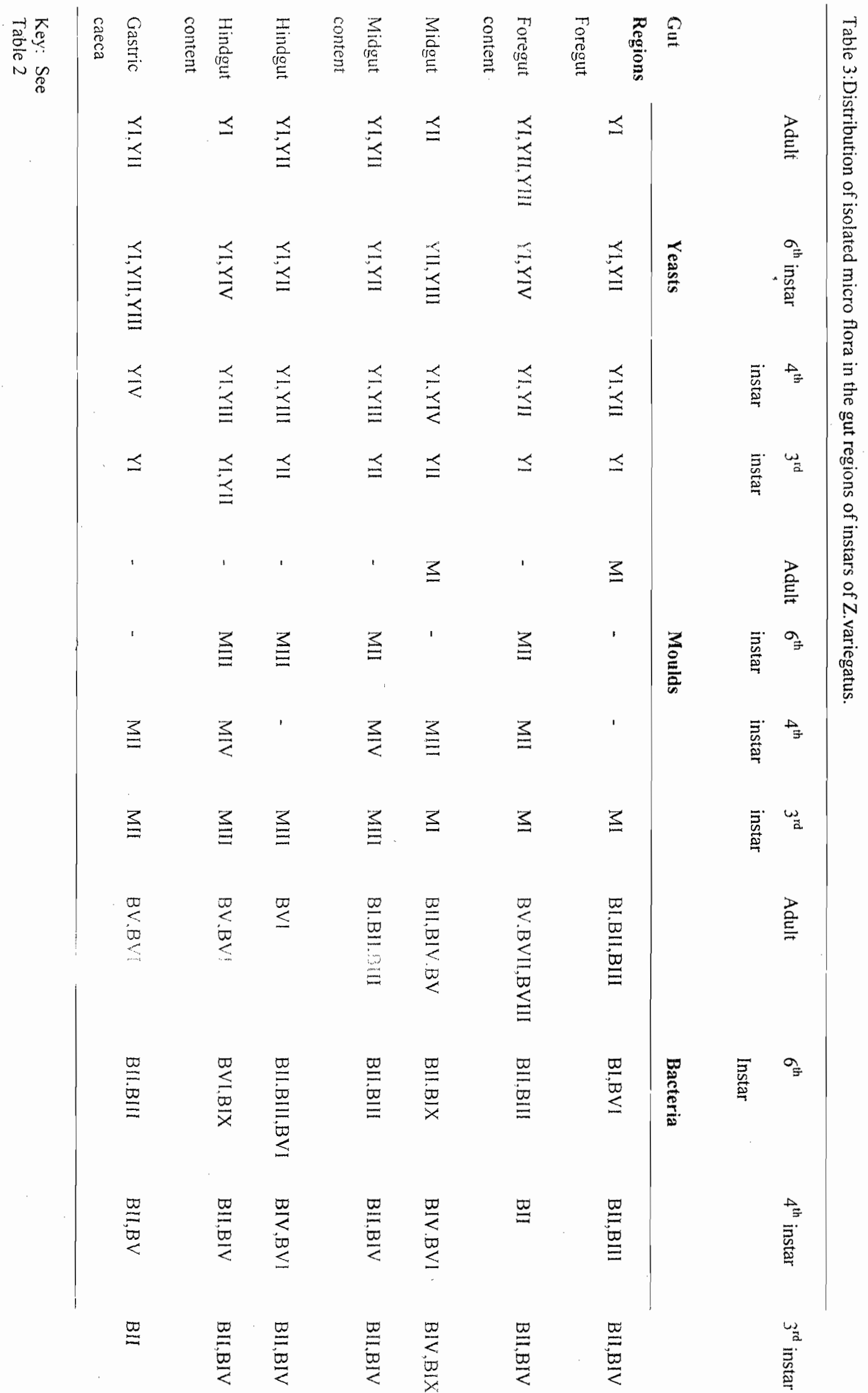


Mead et al (1988) for Schistocerca gregaria and Melanoplus sanguinipes respectively. The isolated microorganisms were randomly distributed in the gut regions and gut contents (Table 3) except for moulds that were virtually absent in the different gut regions of the adult instar. However, there was similarity in the types of microorganism found in all the instars. Results of microbial counts generally did not show any significant differences among the adult and the $6^{\text {th }}$ instars on one hand and the $3^{\text {: }}$ and $4^{\text {th }}$ instars on the other hand $(P \geq 0.05)$. This differences could be due to differences in diets among the instars. The early instars, $1^{\text {st }}-4^{\text {th }}$ are known to prefer Chromolaena odorata while the later instars, $5^{\text {th }}$ to adult feed and grow very well on Manihot esculenta IChapman et al. 1986).

Morphological studies on the alimentary tract of Z.variegatus showed a progressive increase in the size and volume of the different gut regions of the grasshopper moults from the $1^{\text {st }}$ to the adult instar (Idowu, unpublished). Earlier, Idowu (1996) reported that the amount of secretion stored and discharged by the repellent gland of Zonocerus is a function of the size and volume of the gland lumen. Microorganisms are usually taken into the gut of insects along with food (Hunt \& Charnley 1981). Therefore, the types and numbers of microorganisms observed in this study are probably a reflection of the types and amounts of food ingested by the different instars which is also reflection of the capacity of their gut regions. The numbers of the isolated microflora could also be due to contamination from the insect's surrounding. There is a need for a subsequent study on the relationship between microorganisms found in the gut of this insect and those on their food plant/s) and its environment.

It is worth noting the predominance of gramnegative rods in almost all the cultures used (Table3). This is similar to what obtains in other acridids (Mead et. al. 1988). There was also an absence of gram-positive bacteria in all the gut sections of the $3^{\text {rd }}$ and $4^{\text {th }}$ instars as against their significant presence in the $6^{\text {th }}$ and adult instars. Z. variegatus is a polyphagous insect but with preference for particular food plant species such as Manihot esculenta by the later instars $5^{\text {th }}$ - adult while the early instars, $1^{\text {st }}-4^{\text {th }}$ are known to prefer C.odorata (Chapman et al 1986).
Microbes have thigh nutritive potentials (Martin \& Kukor 1984\%. They are a rich source of protein having high levels of other macronutrients as well, such as lipids, carbohydrate and are also good source of critical macronutrients such as unsaturated fatty acids and vitamins (Martin \& Kukor 1984). The fungal enzymes in the gut of termites are known to be very useful for the digestion of plant materials (Breznak et. al. 1994). Proteus $\mathrm{sp}$. Isolated in this work is known to produce proteolytic enzymes. Lactobacillus sp. Also found in the later instars examined in this are known to produce glucosidases (Martin \& Kukor 1984). The ability of $Z$. variegatus to tolerate and digest cyanogenic glucoside contained in M.esculenta has been a puzzle to scientist (Idowu, 1994). Moreso since the grasshopper lacks any enzyme capable of hydrolyzing the cyanide in its gut. It is therefore possible that apart from being a rich source of nutrients to the insects, the microflora in the gut of the grasshopper such as Lactobacillus sp. may play a role in the digestion of the cyanogenic glucoside present in M.esculenta consumed.

Results of this study has shown that the guts of the instars of Z.variegatus are rich in different types of microbes. Although, the function of these microbes still await further elucidation, results of studies on other insects suggests that the microbes might be of immense benefit to the insect particularly in the digestion of its food material.

ACKNOWLEDGEMIENT: The study was supported by a Research Grant from the University of Agriculture, Abeokuta (RG 120)

\section{REFERENCES}

Balogun, R.A. 1972. Digestive carbohydrases and the nature of amylase in the gut homogenate of Zonocerens variegatus (L). Bull. Entomol. Soc. Niger. 3.9|-94

Breznaks, J.A. and Brune, A. 1994. Role of Microorganisms in the Digestion of Ligno-cellulose by Termites. Ann. Rev. of Ent. 39:453-487

Chapman, R.F., Page, W.W.. McCaffery, A.R. 1986 Bionomics of the variegated Grasshopper (Zonocerus variegatus) in west and central Africa Ann. Rev. of Ent. 31:479-505

Harrigan, W. F. and McCance M. E. 1976. Laboratory methods in food and dairy microbiology, London, Academic Press 
Hugh R.and Leifson E., 1953. The taxonomic significance of fermentative versus oxidative inetabolism of carbohydrate by various gram negative bacteria. J. Bacterio!. 66:24-26

Hunt, J. and Charnley, A.K. , 1981. Adundance and distribution of the gut flora of the Desert locust Schistocerca gregaria J. of Invert. Pathology 38:378-385

Idowu, A.B. 1996 The growth pattern of the repellent gland of Zonocerus variegatus Bioscience Res. Comm. $8: 1-6$

Idowu A . B., 1995. Structure of the repellent gland of Zonocerusvar iegatus J. of Afr. Zool. 109:247-252

Idowu, A.B. 1994: Structural and Physiological Studies of the Repellent Gland of the African grasshopper pest, Zonocerus variegatus (L); Ph.D. Thesis, University of Ibadan.

Idowu A.B. Unpublished A study on the population of Zonoceris variegatus (L) in University of Agriculture, Abeokuta.

Krejer-Van rij N.J.W. 1984. The yeasts- a taxonomic study $3^{\text {rd }}$ Edtn. Amsterdam, Elsevier Science Publishers $108 \cdot 1 \mathrm{pp}$
Martin, M.M. and Kukor, J. J, 1984. Role ot mycophagy and Bacteriophagy in invertebrate Nutrition pp257. 263 In J. M. Anderson, A.D.M. Rayner and D Walton (ed.), Animal-Microbial Interactions. Cambridge University Press. Cambridge.

Mead, L. J, Khaachatourians, G.G. and Jones, G.A. 1988. Microbial Ecology of the Gut in the laboratory stocks : of the migratory Grasshopper, Melanop/us sanguinipes (Fab) (Orthoptera: Acrididae) Applied and Enviromental Microbiology 54:1174-118:

Modder, W.W.D. 1977. Changes in somatic tissues of the penultimate instar of the African grasshopper, Zonocerus variegatis $(\mathrm{L})$ (Acridoidea: Pyrgomorphidae). Acrida 7: 253-265

Onions A.H.S, AHsopp D., and Eggins H.O.W. 1981 Smith's Introduction to Industrial Mycology $7^{\text {th }}$ Edtn. E.A., Lundon $398 \mathrm{pp}$.

Sneath P.H.A., Mair N.S, Sharpe M.E and Holt J.G (Edt) 1986 Bergey's manual of systematic bacteriology Vol. 2 Williams and Wilkins Co. Baltimore. 